\title{
BOTULINUM TOXIN FOR THE TEMPORARY TREATMENT OF INVOLUTIONAL LOWER LID ENTROPION: A CLINICAL AND MORPHOLOGICAL STUDY
}

\author{
D. H. W. STEEL ${ }^{1}$, H. B. HOH ${ }^{1,3}$, R. A. HARRAD ${ }^{1}$ and C. R. COLLINS ${ }^{2}$ \\ Bristol
}

\begin{abstract}
SUMMARY
Purpose: A prospective study was designed to evaluate the use of botulinum toxin as a temporary treatment in patients awaiting surgical repair for involutional entropion and to compare its use with lid taping.

Methods: Botulinum toxin was administered to 30 patients with involutional entropion (35 eyelids). These patients had all previously been using lid taping and lubricant ointment as a temporary measure whilst awaiting lid surgery. Patients' symptoms and signs were assessed before and after toxin injection. The date of entropion recurrence was recorded. Eyelid tissue from 8 patients treated with toxin and 3 control patients who had not been given toxin was obtained after surgical entropion repair and examined histologically to ensure the botulinum toxin had no potential detrimental effects on the results of surgery.

Results: The toxin was simple and quick to administer. Anatomical success was achieved in 33 of the 35 eyelids with significant improvements in symptoms and signs. The mean duration of action of the toxin was 12.5 weeks. Lower lid laxity was inversely correlated with duration of toxin action. There were no consistent changes in orbicularis oculi morphology after toxin injection.

Conclusion: Botulinum toxin is a highly effective temporary treatment for involutional entropion with few complications and no adverse effects on the results of surgical entropion repair.
\end{abstract}

Senile or involutional entropion is a common condition and is important both because of its potential corneal complications and because of the disabling symptoms it causes. Surgical repair is the definitive

From: ${ }^{1}$ Bristol Eye Hospital; ${ }^{2}$ Bristol Royal Infirmary, Bristol, UK; ${ }^{3}$ University Malaya, Lembah Pantai, Kuala Lumpur, Malaysia.

Correspondence to: Mr D. H. W. Steel, Bristol Eye Hospital, Lower Maudlin Street, Bristol BS1 2LX, UK. treatment and waiting lists for surgery are the norm. During this waiting period corneal complications may occur. A variety of temporary conservative measures such as lid taping and lubricant ointment are used to alleviate symptoms and prevent ocular complications whilst awaiting surgery. A retrospective study of senile entropion at our hospital highlighted problems with the use of taping and an alternative temporary treatment was sought.

The successful use of botulinum toxin in involutional entropion has been reported $d^{2,3}$ but has not been generally accepted as a form of treatment. A pilot study confirmed that the technique was acceptable to patients and produced encouraging results. ${ }^{1}$ We designed a prospective study to compare the use of botulinum toxin in the temporary treatment of senile entropion with lid taping and lubricant ointment. Eyelid tissue was examined after surgical entropion repair to assess whether there were any detrimental effects on muscle histology which could affect the outcome of entropion surgery.

\section{MATERIALS AND METHODS}

Thirty consecutive patients were recruited from our waiting lists over a 5 month period. This represented 35 eyelids with involutional entropion. Cases of entropion due to other causes were excluded. At the time of listing for surgery, all these patients had been instructed on the use of lid taping and lubricant ointment as a temporary measure whilst awaiting their lid surgery.

Informed consent was obtained and 20 units of botulinum toxin in $0.1 \mathrm{ml}$ was injected subdermally using a 27 gauge needle into the lateral part of the preseptal orbicularis so as to raise a skin bleb (Fig. $1)$. The lateral portion of the lid was chosen to prevent interference with the lacrimal pump associated with the medial part of the orbicularis.

Eye (1997) 11, 472-475 C 1997 Royal College of Ophthalmologists 


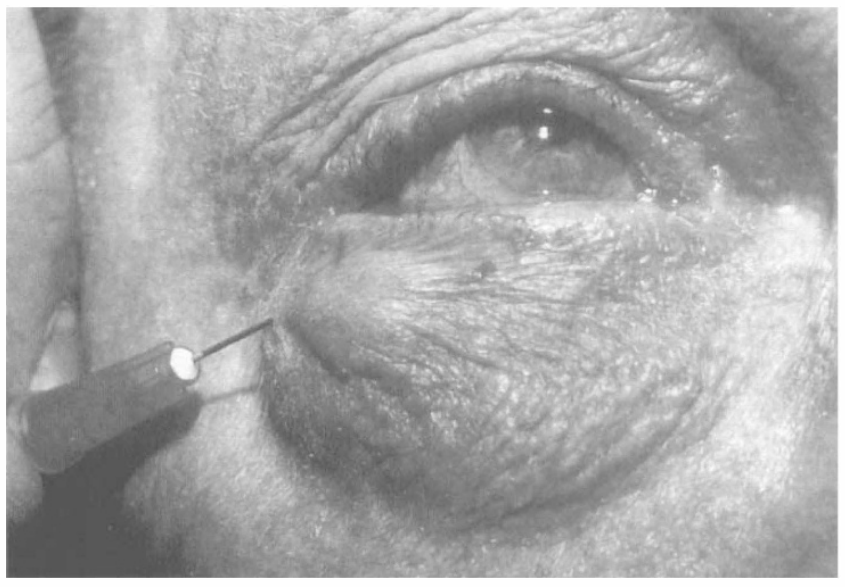

Fig. 1. Technique of botulinum toxin injection.

Patients were evaluated for clinical symptoms and signs associated with the entropion before toxin injection and then again 2 and approximately 10-12 weeks after injection.

Symptoms of discomfort, foreign body sensation, watering, photophobia and blurring were graded as absent, mild, moderate or severe, and scored $0,1,2$ or 3 respectively, giving a cumulative maximum score of 15. Patients were asked about the amount of symptomatic relief obtained and how acceptable they found each treatment to use. These were graded on a sliding visual analogue scale from 0 (poor) to a maximum of 10 (excellent). The presence or absence of conjunctival erythema, punctate corneal staining with fluorescein and corneal vascularisation was noted.

The eyelid was assessed for horizontal laxity by measuring the amount of lateral movement of the central part of the eyelid on horizontal lid traction. In addition downward excursion of the eyelid on downgaze was assessed as a measure of lower lid retractor function. ${ }^{4}$

The time at which the entropion recurred following botulinum toxin was assessed from the history and confirmed by examination.

Paired $t$-tests were used to compare measurements before and after toxin injection.

\section{Histological Method}

Lid tissue from 8 patients in the study who underwent a Quickert's repair (transverse lid split, everting sutures and horizontal lid shortening) of their entropion, after the effect of the toxin had ceased, was obtained for histological analysis. Lid tissue from a further group of patients with entropion who had not been given toxin was also obtained. The blocks of lid tissue were frozen in liquid nitrogen and cryostat sections were cut perpendicular to the lid margin. The sections were stained with haematoxylin and eosin and histochemically with myosin ATPase at $\mathrm{pH}$ 9.5.
The mean of 400 muscle fibre diameters (as measured along the 'minor axis"5) as well as the percentage of muscle fibre area compared with loose connective tissue was estimated for each specimen. The proportion of type 2 muscle fibres for each specimen was also recorded.

\section{RESULTS}

The mean duration of entropion symptoms prior to entry into the trials-was 11 months with a median of 6 months.

\section{Before Botulinum Toxin Injection}

Watering, foreign body sensation and discomfort were experienced by all patients despite using lid taping and lubricant ointment. Twenty-seven patients had inferior punctate epithelial erosions and conjunctival erythema, and 3 patients had early inferior corneal vascularisation.

Patients were generally dissatisfied with lid taping, giving it a low score for the symptomatic relief obtained and the acceptability of the treatment (Table I).

\section{After Botulinum Toxin Injection}

The toxin began to take effect within 24 hours of administration in all patients. Anatomical success, i.e. complete resolution of the entropion, was achieved in 33 of the 35 eyelids ( 29 patients). There was a significant improvement in symptoms with complete resolution of all symptoms in 22 patients (Table I).

The toxin injection was generally perceived by the patients to provide good symptomatic relief and be an acceptable form of treatment (Table I). Twentyone patients were completely satisfied with the toxin treatment, i.e. gave it a score of $10 / 10$ for the amount of symptomatic relief obtained and the acceptability of the treatment.

The mean duration of action of the toxin, i.e. time to entropion recurrence, was 12.5 weeks (range 6-23 weeks). In 3 patients (5 eyelids) in whom surgery was contraindicated, toxin injection was repeated after the initial effect wore off. The mean duration of repeat action in this small group was 27 weeks (range 21-32 weeks).

There was no significant change in lower lid laxity, with mean values of $5.9 \mathrm{~mm}$ before toxin injection and $6.1 \mathrm{~mm}$ after $(p=0.21)$. There was an inverse

Table I. Patient scores

\begin{tabular}{lcc}
\hline & $\begin{array}{c}\text { Before } \\
\text { toxin } \\
\text { injection }^{\mathrm{a}}\end{array}$ & $\begin{array}{c}\text { After } \\
\text { toxin } \\
\text { injection }\end{array}$ \\
\hline $\begin{array}{lcc}\text { Cumulative symptom score (mean) } \\
\text { Amount of symptomatic relief }\end{array}$ & 7.6 & $0.97 \quad(p<0.001)$ \\
$\begin{array}{c}\text { obtained (mean) } \\
\text { Acceptability of treatment (mean) }\end{array}$ & 2.1 & $9.3 \quad(p<0.001)$ \\
\hline
\end{tabular}

${ }^{\mathrm{a}}$ While the patient was being treated with lid taping and lubricant ointment. 
correlation between horizontal lid laxity and the duration of action of the toxin which was statistically significant $\left(r^{2}=0.347, p<0.001\right.$, Pearson's correlation coefficient).

Lower lid retractor function was unaffected by the toxin (mean $4 \mathrm{~mm}$ both before and after toxin), except in 1 patient in whom there was a marked reduction in function from $4.5 \mathrm{~mm}$ to $1 \mathrm{~mm}$. The retractor function returned to normal after 12 weeks. There was no correlation between lower lid retractor function and duration of action of the toxin.

Complications that occurred were few. One patient had increased epiphora after toxin injection secondary to bilateral punctal eversion. This returned to normal as orbicularis function returned. One patient experienced diplopia on dextroelevation secondary to inferior oblique underaction. There was no diplopia in the primary position and symptoms resolved in 3 weeks.

The cost of botulinum toxin is an important consideration. The current cost of one 500 unit vial of botulinum toxin (Dysport, Porton Laboratories), at $£ 176$, is expensive. One 20 unit dose therefore costs approximately $£ 7$. However, in many hospitals where botulinum toxin is used on a regular basis for a variety of conditions, efficient patient management allows the economical use of toxin for temporary entropion correction in toxin clinics.

\section{Histology}

The muscle appeared morphologically normal in all specimens. Muscle fibre dimensions varied considerably in all specimens, including control specimens. There was no difference in mean fibre diameters between toxin-treated and untreated muscle and findings were similar to those previously described for type 1 and type 2 fibres of orbicularis oculi in normals ${ }^{6}$ and those with involutional entropion and ectropion. $^{7}$

The quantity of loose fibrous connective tissue lying between muscle fibres also varied considerably,

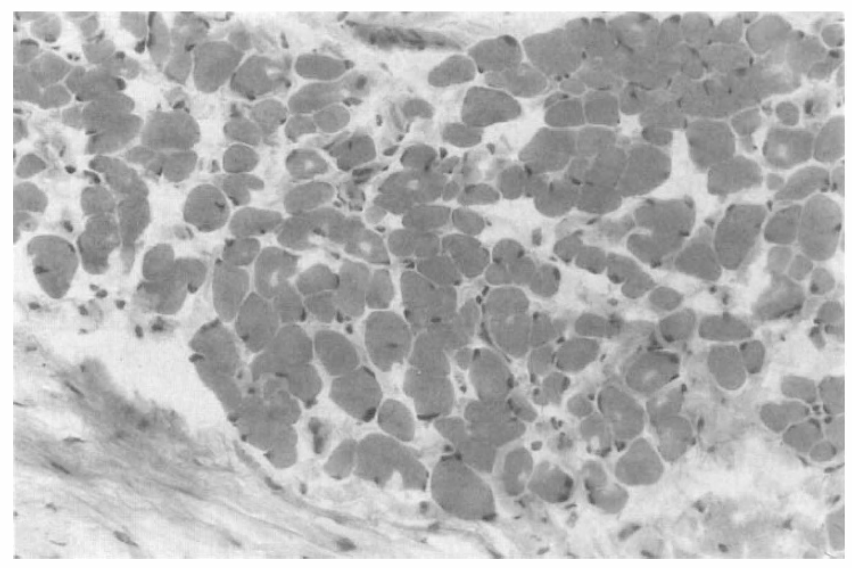

Fig. 2. Transverse section of botulinum toxin treated orbicularis oculi stained with haematoxylin and eosin. but again no difference could be demonstrated between the treated and untreated muscle (Fig. 2).

Histochemical staining demonstrated a random distribution of type 1 and type 2 fibres with a preponderance of the latter, similar to previous studies of orbicularis oculi ${ }^{6,7}$ (Fig. 3). There was no difference in fibre type percentages or fibre type distribution between the control and toxin-treated lids (Table II).

\section{DISCUSSION}

Botulinum toxin has been shown to be a highly effective temporary treatment for involutional entropion with few complications. The toxin was simple and relatively painless to administer allowing its potential use in an outpatient setting by trained nonmedical personnel.

Lid taping has a low patient acceptability: it is cosmetically unsightly, causes skin soreness and, in our experience, elderly patients find it difficult to apply. There was persistence of entropion symptoms and corneal signs despite its use, which disappeared following toxin treatment.

Botulinum toxin produced no long-term consistent change in the morphology of orbicularis oculi muscle. This agrees with previous studies of orbicularis oculi after failed toxin treatment for blepharospasm and is in contrast to reported changes in extraocular muscle with toxin which reflects the unique structure of the external eye muscles. ${ }^{8.9}$ No patient had a permanent relief of their entropion, which is consistent with the full return of orbicularis function. Only one patient has as yet had a recurrence of their entropion following surgery, although follow-up time is short (range 14-21 months). That orbicularis morphology is normal following toxin use means that there will be no detrimental effects on the results of surgery.

Horizontal lower lid laxity was not associated with an increased prevalence of medial ectropion as might have been expected.

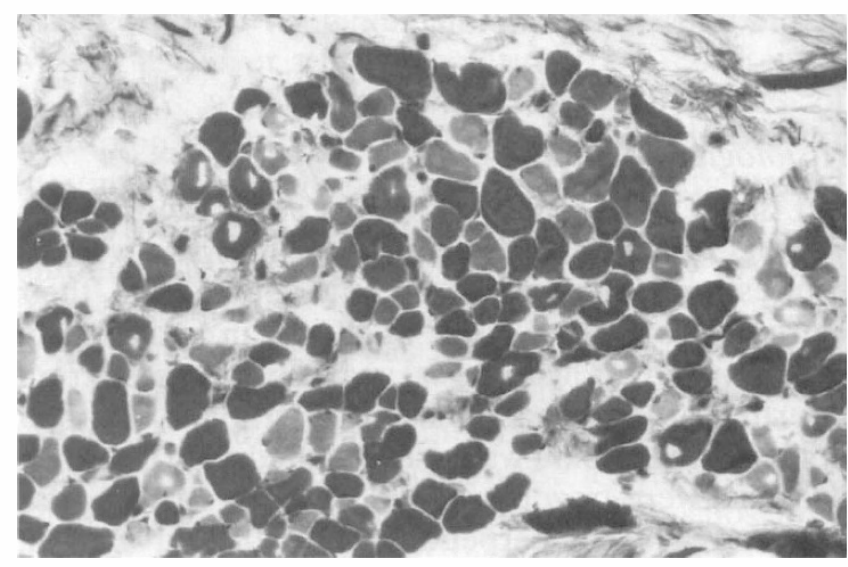

Fig. 3. Transverse section of botulinum toxin treated orbicularis oculi stained with myosin ATPase at pH 9.5 with metachromatic counterstain. 
Table II. Results of histological analysis of lid tissue

\begin{tabular}{|c|c|c|c|c|}
\hline Patient & $\begin{array}{l}\text { Time after toxin injection } \\
\text { (weeks) }\end{array}$ & $\begin{array}{l}\text { Mean fibre diameter } \\
\qquad(\mu \mathrm{m})\end{array}$ & $\begin{array}{c}\text { Area of muscle bundle } \\
\text { occupied by muscle fibres } \\
(\%)\end{array}$ & $\begin{array}{c}\text { Type } 2 \text { fibres } \\
(\%)\end{array}$ \\
\hline \multicolumn{5}{|c|}{ Botulinum toxin treated patients } \\
\hline 1 & 16 & 21 & 14 & 67 \\
\hline 2 & 17 & 30.9 & 26.5 & 77 \\
\hline 3 & 23 & 20.1 & 22 & 78 \\
\hline 4 & 25 & 33 & 24 & 82 \\
\hline 5 & 28 & 31.8 & 17 & 84 \\
\hline 6 & 16 & 13.5 & 45 & 74 \\
\hline 7 & 30 & 24 & 19 & 88 \\
\hline 8 & 24 & 19 & 28 & 75 \\
\hline Mean & 22.4 & 24.2 & 24.4 & 78.1 \\
\hline SD & & 4.9 & & 4.5 \\
\hline $95 \%$ CI & & $19.3-29.1$ & & $73.6-82.6$ \\
\hline \multicolumn{5}{|c|}{ Control patients } \\
\hline 1 & $\mathrm{n} / \mathrm{a}$ & 33 & 27.8 & 88 \\
\hline 2 & $\mathrm{n} / \mathrm{a}$ & 20.4 & 19 & 76 \\
\hline 3 & $\mathrm{n} / \mathrm{a}$ & 22 & 26 & 80 \\
\hline Mean & & 25.1 & 24.3 & 71.3 \\
\hline SD & & 6.9 & & 6.1 \\
\hline $95 \%$ CI & & $18.4-31.8$ & & $65.2-77.4$ \\
\hline
\end{tabular}

95\% CI, 95\% confidence interval; n/a, not applicable.

Toxin injection has no significant effect on the magnitude of lid laxity or inferior lid retractor function. The mean duration of action of the botulinum toxin was 12.5 weeks; the mean waiting time for surgery was found to be 10 weeks in a previous audit of entropion at our hospital. ${ }^{1}$ Increased horizontal lid laxity was correlated significantly with a shorter duration of action of the toxin. This finding is not surprising, since lid laxity is an aetiological factor in entropion. Botulinum toxin is effective in involutional entropion by producing a temporary paralysis of the overriding preseptal orbicularis oculi muscle. When there is a large amount of existing lid laxity, the action of the partially recovered orbicularis oculi may be sufficient to cause entropion.

Toxin injection was unsuccessful in one patient with a bilateral entropion. This patient had signs of chronic blepharitis and close examination revealed early cicatricial changes overlying the inferior tarsus. The patient should not have been included in the study.

Longer duration of action of botulinum toxin has been reported following repeated injection in essential blepharospasm. ${ }^{10}$ In three patients who had repeat toxin injection for entropion the duration of action was increased to a mean of 27 weeks. In a small group of patients who either do not want surgery or are unable to cooperate with it, botulinum toxin may provide a long-term alternative to surgery.

The long duration of entropion symptoms prior to treatment consists of the sum of the time prior to patient presentation to their general practitioner, the time awaiting initial hospital consultation and the waiting time prior to surgery on the waiting list. This long period of ocular morbidity when the eye is at risk of serious complications is avoidable. In our hospital we now routinely see patients in a toxin clinic immediately following receipt of a referral letter. They are injected with toxin and their names are put on the waiting list for surgery. This practice both reduces the waiting time between referral and surgery and brings about symptomatic relief.

Declaration: The authors hold no proprietary interest in botulinum toxin.

Key words: Botulinum toxin, Involutional entropion.

\section{REFERENCES}

1. Hoh B, Steel DHW, Potts MJ, Harrad RA. The use of botulinum toxin in involutional entropion. Orbit 1995;14(3):131-6.

2. Neetens A, Rubbens MC, Smet H. Botulinum A toxin treatment of spasmodic entropion of the lower eyelid. Bull Soc Belge Ophtalmol 1987;224:105-9.

3. Clarke JR, Spalton DJ. Treatment of senile entropion with botulinum toxin. Br J Ophthalmol 1988;72:361-2.

4. Shore JW. Changes in lower eyelid resting position, movement and tone with age. Am J Ophthalmol 1985;99:415-23.

5. Song SK, Shimada N, Anderson PJ. Orthogonal diameter in the analysis of muscle fibre size and form. Nature 1963;200:1220-1.

6. Polgar J, Johnson MA, Weightman D, Appleton D. Data on fibre size in thirty-six human muscles: an autopsy study. J Neurol Sci 1973;19:307-18.

7. Manners RM, Weller RO. Histochemical staining of orbicularis oculi muscle in ectropion and entropion. Eye 1994;8:332-5.

8. Harri CP, Alderson K, Nebeker J, Anderson RL. Histologic features of human orbicularis oculi treated with botulinum A toxin. Arch Ophthalmol 1991;109: 393-6.

9. Porter JD, Strebeck S, Capra NF. Botulinum induced changes in monkey eyelid muscle. Arch Ophthalmol 1991;109:396-404.

10. Frueh BR, Musch DC. Treatment of facial spasm with botulinum toxin: an interim report. Ophthalmology 1986;93:917-23. 